TITLE:

\title{
Luminescence Color Tuning from Blue to Near Infrared of Stable Luminescent Solid Materials Based on Bis-o-Carborane-Substituted Oligoacenes
}

\section{AUTHOR(S):}

Naito, Hirofumi; Nishino, Kenta; Morisaki, Yasuhiro; Tanaka, Kazuo; Chujo, Yoshiki

\section{CITATION:}

Naito, Hirofumi ...[et al]. Luminescence Color Tuning from Blue to Near Infrared of Stable Luminescent Solid Materials Based on Bis-o-Carborane-Substituted Oligoacenes.

Chemistry - An Asian Journal 2017, 12(16): 2134-2138

\section{ISSUE DATE:}

2017-08-17

\section{URL:}

http://hdl.handle.net/2433/235027

\section{RIGHT:}

This is the peer reviewed version of the following article: Hirofumi Naito, Kenta Nishino, Yasuhiro Morisaki, Kazuo Tanaka and Yoshiki, Luminescence Color Tuning from Blue to Near Infrared of Stable Luminescent Solid Materials Based on Bis-o-Carborane-Substituted Oligoacenes, ChujoChem.AsianJ.2017, 12, 2134 -2138, which has been published in final form at https://doi.org/10.1002/asia.201700815. This article may be used for non-commercial purposes in accordance with Wiley Terms and Conditions for Use of Self-Archived Versions.; The full-text file will be made open to the public on 26 June 2018 in accordance with publisher's 'Terms and Conditions for Self-Archiving'.; の論文は出版社版でありません。引用の際には出版社版をご確認ご利用ください。; This is not the published version. Please cite only the published version. 


\section{Design for Presenting Short-Wavelength \\ Luminescence by Utilizing Heavier Atom of the Same Group Element Based on Conjugated Molecule}

Madoka Yamaguchi, Kazuo Tanaka, * Yoshiki Chujo*

Department of Polymer Chemistry, Graduate School of Engineering, Kyoto University, Katsura, Nishikyo-ku, Kyoto 615-8510, Japan

E-mail: kazuo123@chujo.synchem.kyoto-u.ac.jp (for K.T.); chujo@chujo.synchem.kyoto-u.ac.jp (for Y.C.)

Key words: boron; chalcogen; conjugation; solid-state emission 


\begin{abstract}
Introduction of heavy atoms often induces red shift in the emission spectra with conjugated molecules. Conversely, we report here the blue-shifting effect on the absorption and emission band by employing a heavier atom in the same element group based on the conjugated organic dye. The boron complexes having the oxygen- and sulfur-bridged structures in the ligand moiety were synthesized, and their optical properties were compared. It was observed that significant optical bands were observed in the shorter wavelength region from the sulfur-bridged complex than those from the oxygen one in the absorption and luminescence spectra. Theoretical calculation results proposed that replacement of the bridging atom to the heavier one should reduce molecular planarity because of the larger atom size. As a result, degree of electronic conjugation could decrease, followed by blue-shifted optical bands. Finally, the blueemissive crystal was demonstrated.
\end{abstract}




\section{INTRODUCTION}

Blue-color emissive dyes are versatile as a host material in a cascade of energy transfer for producing any color. ${ }^{1}$ By combination with green and red-color emissive materials, white-light luminescence which is applicable for illumination can be generated. ${ }^{2-5}$ Therefore, the development of blue-color emissive organic materials is an area of particular interest with high relevance, especially for improving quality of organic luminescent devices. So far, numerous numbers of materials having blue-color emission were reported based on phosphorescence ${ }^{6-8}$ and thermally-activated delayed fluorescence. ${ }^{9-11}$ However, there remains a challenge to have blue-color emission in the condensed state because inevitable intermolecular interaction frequently induced red shifts in the optical spectra and aggregation-caused quenching (ACQ). Thus, establishment of a new design strategy not only for obtaining blue emission but also for observing invariable optical properties even in the solid state is still of great significance.

To overcome ACQ and obtain solid-state luminescence, a class of compounds having aggregation-induced emission (AIE), in which intense emission was observed only in the solid state, while emission quenching occurred in the solution, has attracted attention. ${ }^{12-16}$ By employing AIE-active building blocks, various types of functional luminescent materials have been developed. ${ }^{17-22}$ Recently, we have reported several AIE-active boron complexes, ${ }^{23-27}$ and unique luminescent properties were found from boron pyridinoiminates BPI and FBPI (Scheme 1). ${ }^{28}$ It was found that the pristine complex BPI was the AIE-active molecule. From theoretical calculations, it was proposed that structural relaxation should proceed after photo-excitation, and subsequently excitation energy was consumed via the non-radiative processes. Based on this assumption, the ring 
fusion structure was introduced into the ligand moiety to inhibit structural relaxation. Accordingly, it was clearly indicated that the opposite behavior from FBPI, such as bright emission only in the solution state and critical ACQ in the solid similarly to conventional organic dyes, can be induced by the ring fusion at the ligand moiety. Thus, it can be said that boron pyridinoiminate should be a property-tunable "element-block", which is a minimum functional unit composed of heteroatoms, ${ }^{29,30}$ for realizing solid-state emission $^{31}$ and both solution- and solid-state-specific luminescent materials based on the single ligand complex. ${ }^{32}$ According to these data, we focused on the effect of the ring fusion on the solid-state luminescent property. We presumed that optical properties can be tuned by precisely modulating the bridged structure. ${ }^{33}$ To evaluate validity of this assumption, the chalcogen-bridged boron pyridinoiminate complexes were designed.

\section{Scheme 1}

Herein, the synthesis and optical properties of the boron complexes with the oxygen(O-BPI) and sulfur-bridged (S-BPI) pyridinoiminate ligand are reported (Scheme 1). From the UV-vis absorption and photoluminescence (PL) measurements, electronic structures were investigated. Accordingly, it was observed that blue-shifting effects on optical spectra were induced by the sulfur bridge. Theoretical calculation suggested that molecular planarity could decrease by replacing the bridged atom to sulfur. As a result, $\pi$-conjugation was weakened and subsequently blue-shifting effects were induced. In the commodity organic dyes, replacement of the heavier element often induced red shifts in the optical spectra, whereas the opposite property especially in the solid-state luminescence was obtained in this study. The new strategy for tuning luminescent color 
without critical loss of emission efficiency was presented by utilizing heteroatoms.

\section{RESULTS AND DISCUSSION}

Boron complexes were synthesized according to Scheme 2. The ligands were prepared through the coupling reactions with 11-chlorodibenzocalcepine and lithiated methylpyridine. By treating these ligands with $\mathrm{BF}_{3} \cdot \mathrm{OEt}_{2}$, the boron complexes were obtained. The products were characterized by ${ }^{1} \mathrm{H},{ }^{13} \mathrm{C}$, and ${ }^{11} \mathrm{~B}$ NMR spectroscopies (Charts S1-S6) and mass measurements. From these data, it was confirmed that the products had designed structures. Both products showed good solubility in common organic solvents such as chloroform, dichloromethane, tetrahydrofuran and acetonitrile, and decomposition was hardly observed in the air and during analyses. Therefore, it was concluded that both boron complexes had high stability enough for evaluating the series of optical properties.

\section{Scheme 2}

To examine electronic structures in the ground state, UV-vis absorption spectra with O-BPI and S-BPI in the solution state were measured (Table 1). From the spectra in $\mathrm{CHCl}_{3}\left(1.0 \times 10^{-5} \mathrm{M}\right)$, large absorption bands attributable to $\pi-\pi^{*}$ transition were observed from both compounds (Figure 1a). S-BPI showed the smaller absorption band in the shorter wavelength region than O-BPI. To evaluate energy levels of highest occupied molecular orbital (HOMO) and lowest unoccupied molecular orbital (LUMO) of both complexes, cyclic voltammetry (CV) was carried out with the solution samples (Figure 2 and Table 2). From the onset values of redox waves, energy levels were 
estimated. Accordingly, it was shown that S-BPI possessed lower HOMO and higher LUMO levels than O-BPI. These data clearly indicate that O-BPI had a narrower band gap than S-BPI.

Figures 1 and 2, Tables 1 and 2

To theoretically support these optical and electrochemical properties, quantum chemical calculations with the density functional theory (DFT) method at the B3LYP/6$31 \mathrm{G}(\mathrm{d})$ level were performed (Figure 3$).{ }^{34}$ Corresponding to the experimental data, SBPI presented a narrower band gap originating from higher HOMO and lower LUMO levels. To estimate influence on the molecular structure by replacing oxygen to sulfur, the bond angles at the chalcogen-bridged moiety and the dihedral angles between the phenyl group and the boron-involving six-membered ring were focused (Figure 4). It was found that the bond angle with sulfur was smaller than that of oxygen. In addition, the dihedral angles in S-BPI was larger than that of $\mathbf{O - B P I}$. These data mean that the complex structure should be distorted by introducing the sulfur bridge. Because of the larger atom size of sulfur, larger degree of molecular distortion should be induced. Hence, the larger band gap, followed by blue-shifted emission was observed from S-BPI.

Figures 3 and 4

To examine electronic properties in the excited state, photoluminescence (PL) spectra were measured with the solution samples $\left(1.0 \times 10^{-5} \mathrm{M}\right.$ in $\left.\mathrm{CHCl}_{3}\right)$ containing boron complexes (Figure 1a and Table 1). Basically, both compounds showed small Stokes 
shifts, indicating that structural relaxation should be suppressed by the chalcogen bridging. ${ }^{28}$ This also means that molecular conformations should be preserved after excitation. Similarly to the absorption spectra, the emission band of S-BPI was observed in the shorter wavelength region than that of O-BPI. The distorted structure represented as larger dihedral angles in $\mathbf{S}$-BPI contributed to restriction of $\pi$-conjugation. As a consequence, emission was obtained in the blue region. The luminescence quantum yields of boron complexes were about 0.10 . In the absence of the bridging atom, slight emission $(\Phi=0.01)$ was observed from BPI, while the ring fusion contributed to drastic enhancement of the efficiency $(\Phi=0.68)$ as observed in FBPI. It was assumed that introduction of the chalcogen bridge could produce room to cause molecular tumbling. Thereby, comparing to the emission efficiency of the complex having the fused ring structure, those of the bridged complexes could decrease. To evaluate influence of molecular motions on emission efficiency, PL spectra were measured in 2methyltetrahydrofuran (2-MeTHF) at $77 \mathrm{~K}\left(1.0 \times 10^{-5} \mathrm{M}\right.$, Figure 5 and Table 3$)$. Under frozen condition, both complexes showed much larger emission bands in the shorter wavelength regions than those at room temperature. This fact means that molecular motion should be responsible for excitation decay. It was found that boron complexes presented phosphorescence at low temperature (Figure 6 and Table 4). According to the previous report on boron pyridinoiminate, it is implied that the existence of the lone-pair electrons on pyridine or imine groups might enhance intersystem crossing rates to the triplet-excited state. ${ }^{28}$ It should be mentioned that the peak wavelengths of emission bands both in chloroform and 2-MeTHF were similar, indicating that solvatochromicity in luminescence was not observed from O-BPI and S-BPI. This fact means that emission properties of these compounds hardly have charge transfer character. 
Figures 5 and 6, Tables 3 and 4

Emission properties were examined in the crystal state (Figure 1b and Table 1). From the PL spectra in the crystalline state, it was observed that S-BPI showed the emission band in the shorter wavelength region than O-BPI similarly in the solution state. Apparently, blue-color emission was obtained from S-BPI (Figure 1c). Both compounds showed slightly weaker emission $\left(\Phi_{\mathrm{PL}}=0.05\right)$ in the crystalline state than that in the solution state $\left(\Phi_{\mathrm{PL}} \approx 0.10\right)$, indicating that these molecules are not an AIE-active molecule, similarly to FBPI. ${ }^{28}$ ACQ should occur due to intermolecular interaction in the closed packing. To evaluate influence of intermolecular interaction in the solid state on emission quenching, optical properties were monitored in the poly(methyl methacrylate) (PMMA) matrix (Figure 7, Table 5). Significant emission bands with similar emission efficiencies (O-BPI: $\Phi_{\mathrm{PL}}=0.45$; S-BPI: $\left.\Phi_{\mathrm{PL}}=0.44\right)$ were detected from both film samples. It was likely that each boron complex would be spatially isolated in the polymer matrices, and less intermolecular interaction should occur similarly to the previous AIE-active boron complexes. ${ }^{35-37}$ In addition, molecular motions can be efficiently suppressed. Thus, intense emission clearly indicates that intermolecular interaction induces ACQ in the solid state of boron complexes. The kinetics were estimated from the degree of the rates of radiative decay $\left(k_{\mathrm{r}}\right)$ and non-radiative decay $\left(k_{\mathrm{nr}}\right)$ processes in each state according to emission lifetimes (Table 6). In all states, larger $k_{\mathrm{nr}}$ values were obtained originating from low $\Phi_{\mathrm{PL}}$. In the solution state, it was found that $k_{\mathrm{nr}}$ of $\mathbf{S}$-BPI was larger than that of $\mathbf{O}$ BPI. It is likely that the distorted structure should be unfavorable for accelerating the emission process. Meanwhile, in the crystalline state, $k_{\mathrm{nr}}$ of $\mathbf{O - B P I}$ was larger, implying 
that ACQ might occur in O-BPI because of the relative planar structure.

Figure 7, Tables 5 and 6

\section{CONCLUSION}

It was demonstrated that emission of boron pyridinoiminate complexes in the shorterwavelength region was induced by using heavier element as a bridge. From structural estimation with theoretical calculations, the sulfur bridge played a critical role in distortion of the molecular skeleton, and restricted $\pi$-conjugation should be responsible for the shorter-wavelength region. Heavy atoms often induced bathochromic shifts in the optical spectra, meanwhile blue-shifted optical bands were demonstrated from the sulfurcontaining molecule by applying the difference in atomic size for modulating molecular planarity. From these results, it can be said that our findings described here could be valid for molecular design of luminescent materials for advanced opto-electronic devices.

\section{ACKNOWLEDGMENTS}

This work was partially supported by the Mitsubishi Foundation (for K.T.) and a Grantin-Aid for Scientific Research (B) (JP17H03067) and on Innovative Areas "New Polymeric Materials Based on Element-Blocks (No.2401)” (JP24102013). 


\section{REFERENCES}

1. Y. Kawamura, S. Yanagida, S. R. Forrest, J. Appl. Phys. 2002, 92, 87-93.

2. S.-J. Su, E. Gonmori, H. Sasabe, J. Kido, Adv. Mater. 2008, 20, 4189-4194.

3. H. Sasabe, J. Takamatsu, T. Motoyama, S. Watanabe, G. Wagenblast, N. Langer, O. Molt, E. Fuchs, C. Lennarts, J. Kido, Adv. Mater. 2010, 22, 5003-5007.

4. G. Schwartz, S. Reineke, T. C. Rosenow, K. Walzer, K. Leo, Adv. Funct. Mater. 2009, 19, 1319-1333.

5. G. Schwartz, M. Pfeiffer, S. Reineke, K. Walzer, K. Leo, Adv. Mater. 2007, 19, $3672-3676$.

6. $\quad$ K. S. Yook, J. Y. Lee, Adv. Mater. 2012, 24, 3169-3190.

7. C.-H. Yang, Y.-M. Cheng, Y. Chi, C.-J. Hsu, F.-C. Fang, K.-T. Wong, P.-T. Chou, C.-H. Chang, M.-H. Tsai, C.-C. Wu, Angew. Chem. Int. Ed. 2007, 46, $2418-421$.

8. T. Tsuboi, W. Huang, Isr. J. Chem. 2014, 54, 885-896.

9. Q. Zhang, B. Li, S. Huang, H. Nomura, H. Tanaka, C. Adachi, Nat. Photonics 2014, 8, 326-332.

10. C. Adachi, Jpn. J. Appl. Phys. 2014, 53, 060101.

11. Y. Im, M. Kim, Y. J. Cho, J.-A Seo, K. S. Yook, J. Y. Lee, Chem. Mater. 2017, $29,1946-1963$.

12. J. Mei, N. L. C. Leung, R. T. K. Kwok, J. W. Y. Lam, B. Z. Tang, Chem. Rev. 2015, 115, 11718-11940.

13. H. Eguchi, H. Nishiyama, S. Inagi, I. Tomita, Asian J. Org. Chem. 2016, 6, $165-168$.

14. J. Mei, Y. Hong, J. W. Y. Lam, A. Qin, Y. Tang, B. Z. Tang, Adv. Mater. 2014, $26,5429-5479$.

15. R. Hu, N. L. C. Leung, B. Z. Tang, Chem. Soc. Rev. 2014, 43, 4494-4562. 
16. S. Mukherjee, P. Thilagar, J. Mater. Chem. C 2016, 4, 2647-2662.

17. H. Imoto, K. Nohmi, K. Kizaki, S. Watase, K. Matsukawa, S. Yamamoto, M. Mitsuishi, K. Naka, RSC Adv. 2015, 5, 94344-94350.

18. H. Imoto, K. Kizaki, S. Watase, K. Matsukawa, K. Naka, Chem. Eur. J. 2015, 21, $12105-12111$.

19. S. Shimizu, T. Iino, A. Saeki, S. Seki, N. Kobayashi, Chem. Eur. J. 2015, 21, 2893-2904.

20. W. A. Morris, M. Sabat, T. Butler, C. A. Derosa, C. L. Fraser, J. Phys. Chem. C 2016, 120, 14289-14300.

21. W. A. Morris, M. Kolpacznska, C. L. Fraser, J. Phys. Chem. C 2016, 120, $22539-22548$.

22. T. Butler, W. A. Morris, J. Samonina-Kosicka, C. L. Fraser, ACS Appl. Mater. Interfaces 2016, 8, 1242-1251.

23. R. Yoshii, A. Nagai, K. Tanaka, Y. Chujo, Chem. Eur. J. 2013, 19, 4506-4512.

24. R. Yoshii, A. Hirose, K. Tanaka, Y. Chujo, Chem. Eur. J. 2014, 20, 8320-8324.

25. R. Yoshii, A. Hirose, K. Tanaka, Y. Chujo, J. Am. Chem. Soc. 2014, 136, $18131-18139$.

26. K. Tanaka, K. Nishino, S. Ito, H. Yamane, K. Suenaga, K. Hashimoto, Y. Chujo, Faraday Discuss. 2017, 196, 31-42.

27. K. Tanaka, Y. Chujo, NPG Asia Mater. 2015, 7, e223.

28. M. Yamaguchi, S. Ito, A. Hirose, K. Tanaka, Y. Chujo, Mater. Chem. Front. 2017, $1,1573-1579$.

29. Y. Chujo, K. Tanaka, Bull. Chem. Soc. Jpn. 2015, 88, 633-643.

30. M. Gon, K. Tanaka, Y. Chujo, Polym. J. 2018, 50, 109-126.

31. S. Ohtani, M. Gon, K. Tanaka, Y. Chujo, Chem. Eur. J. 2017, 23, 11827-11833. 
32. K. Suenaga, K. Tanaka, Y. Chujo, Eur. J. Org. Chem. 2017, 2017, 5191-5196.

33. T. Matsumoto, H. Takamine, K. Tanaka, Y. Chujo, Org. Lett. 2015, 17, $1593-1596$.

34. M. J. Frish, et al. GAUSSIAN 09 (Revision D.01), Gaussian, Inc., Wallingford CT, 2009.

35. K. Suenaga, R. Yoshii, K. Tanaka, Y. Chujo, Macromol. Chem. Phys. 2016, 217, $414-417$.

36. R. Yoshii, K. Suenaga, K. Tanaka, Y. Chujo, Chem. Eur. J. 2015, 21, 7231-7237.

37. M. Yamaguchi, S. Ito, A. Hirose, K. Tanaka, Y. Chujo, J. Mater. Chem. C 2016, $3,5314-5319$. 


\section{FIGURES AND TABLES}

Scheme 1. Chemical structures of boron pyridinoiminate complexes

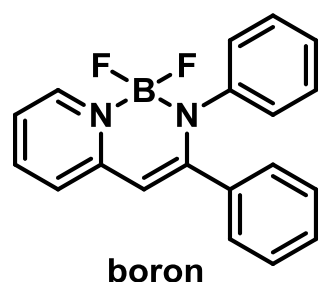

pyridinoiminate

(BPI)<smiles>FB1c2ccccc2C=C2c3ccccc3Oc3ccccc3N(F)N12</smiles><smiles>FB1c2ccccc2-c2ccccc2C=c2n3c(n21)=CC=CC=C3</smiles>

FBPI<smiles>FB1c2ccccc2Sc2ccccc2C=c2n3c(n21)=CC=CC=C3</smiles>

S-BPI 
Scheme 2. Syntheses of boron complexes<smiles>O=C(Cl)c1ccccc1F</smiles><smiles>Nc1ccccc1O</smiles>

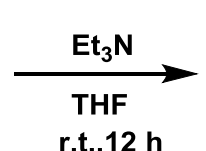<smiles>O=C(Nc1ccccc1O)c1ccccc1F</smiles>

$1 a$<smiles>O=C(Nc1ccccc1O)c1ccccc1F</smiles><smiles>O=C1Nc2ccccc2Oc2ccccc21</smiles>

2a<smiles>ClC1=Nc2ccccc2Oc2ccccc21</smiles>

3a

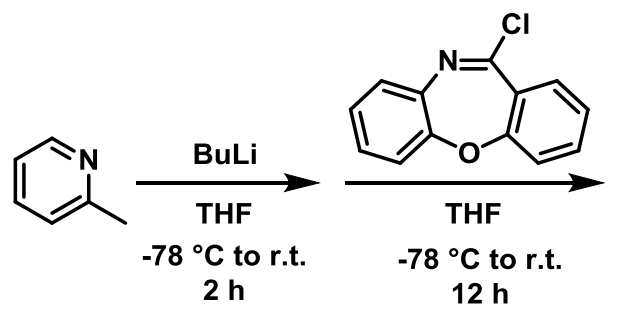<smiles>CCOCc1ccccc1/C(=C/c1ccccn1)Nc1ccccc1OCC(C)N(CC)CC</smiles>

$4 a$<smiles>FB1c2ccccc2C=C2c3ccccc3Oc3ccccc3N(F)N12</smiles>

O-BPI<smiles>O=C1Nc2ccccc2Sc2ccccc21</smiles>

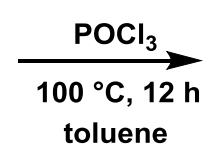<smiles>ClC1=Nc2ccccc2Sc2ccccc21</smiles>

$1 b$

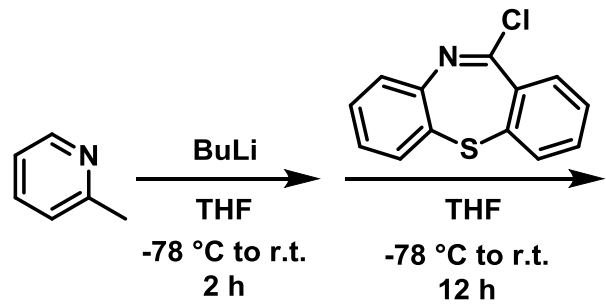

$12 \mathrm{~h}$<smiles>CCOCCN(CC)Cc1ccccc1/C(=C/c1ccccn1)Nc1ccccc1Br</smiles>

2b<smiles>FB1c2ccccc2C=C2c3ccccc3Sc3ccccc3N12</smiles> 

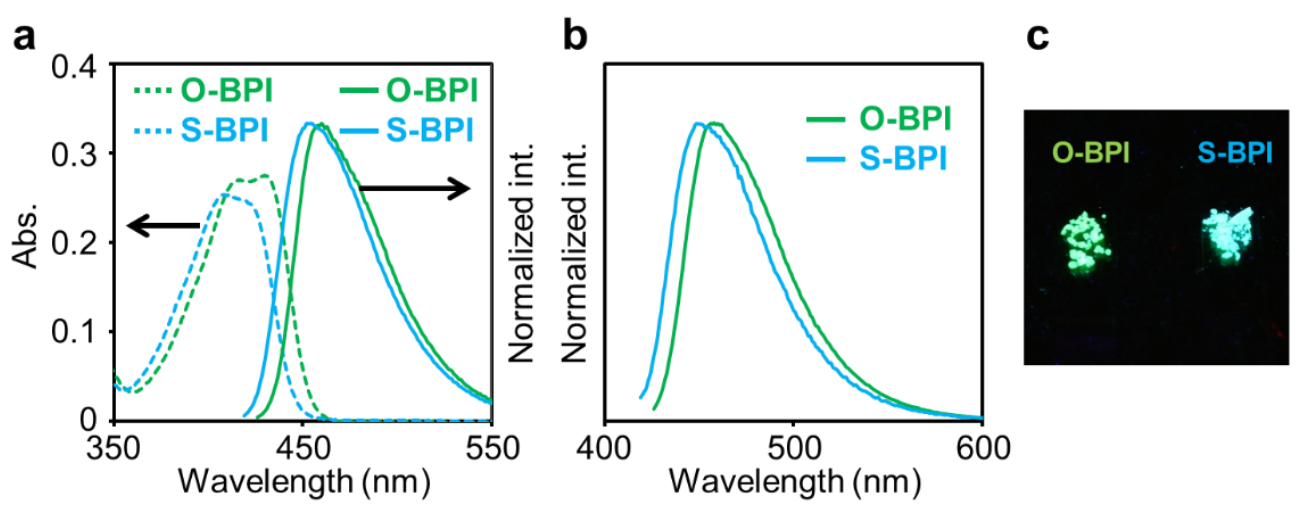

Figure 1. (a) UV-vis absorption and PL spectra of O-BPI and S-FBPI in $\mathrm{CHCl}_{3}(1.0 \times$ $10^{-5} \mathrm{M}$ ) and (b) PL spectra in the crystalline state. (c) Photographs of the crystals under UV irradiation (365 nm). 
Table 1. Optical properties of the complexes

\begin{tabular}{|c|c|c|c|c|c|c|c|c|}
\hline & $\begin{array}{l}\lambda_{\mathrm{abs}, \max } \\
(\mathrm{nm})^{a}\end{array}$ & $\begin{array}{c}\begin{array}{c}\varepsilon_{\max } \\
\left(\mathrm{M}^{-1} \mathrm{~cm}^{-1}\right)^{b}\end{array}\end{array}$ & $\begin{array}{c}\lambda_{\mathrm{PL}} \\
(\mathrm{nm})^{a}\end{array}$ & $\Phi_{\mathrm{PL}}^{a, e}$ & $\begin{array}{c}\tau \\
(\mathrm{ns})^{a, f}\end{array}$ & $\begin{array}{c}\lambda \mathrm{PL} \\
(\mathrm{nm})^{g}\end{array}$ & $\Phi_{\mathrm{PL}}^{e, g}$ & $\begin{array}{c}\tau \\
(\mathrm{ns})^{f, g}\end{array}$ \\
\hline O-BPI & 430 & 27,400 & $460^{c}$ & 0.10 & 0.82 & 483 & 0.05 & $\begin{array}{l}0.68(70 \%) \\
1.67(30 \%)\end{array}$ \\
\hline S-BPI & 409 & 25,200 & $454^{d}$ & 0.11 & 0.67 & 476 & 0.05 & $\begin{array}{l}0.60(19 \%) \\
1.70(81 \%)\end{array}$ \\
\hline $\begin{array}{l}{ }^{a} \text { Measu } \\
{ }^{b} \text { Detern } \\
{ }^{c} \text { Excite } \\
{ }^{d} \text { Excite } \\
{ }^{e} \text { Detern } \\
{ }^{f} \text { Excitec } \\
{ }^{g} \text { Measu }\end{array}$ & $\begin{array}{l}\text { din ch } \\
\text { ed at } \\
\text { t } 416 \\
\text { t } 409 \\
\text { t } 375 \\
\text { d with }\end{array}$ & $\begin{array}{l}\text { loroform }\left(10^{-}\right. \\
\text {he peak wave } \\
\mathrm{am} \text {. } \\
\mathrm{hm} \text {. } \\
\text { an absolute va } \\
\mathrm{am} \text {. } \\
\text { the crystalline }\end{array}$ & $\begin{array}{l}\text { M). } \\
\text { ngth. } \\
\text { ue with } \\
\text { sample. }\end{array}$ & inte & $\mathrm{spl}$ & metl & & \\
\hline
\end{tabular}



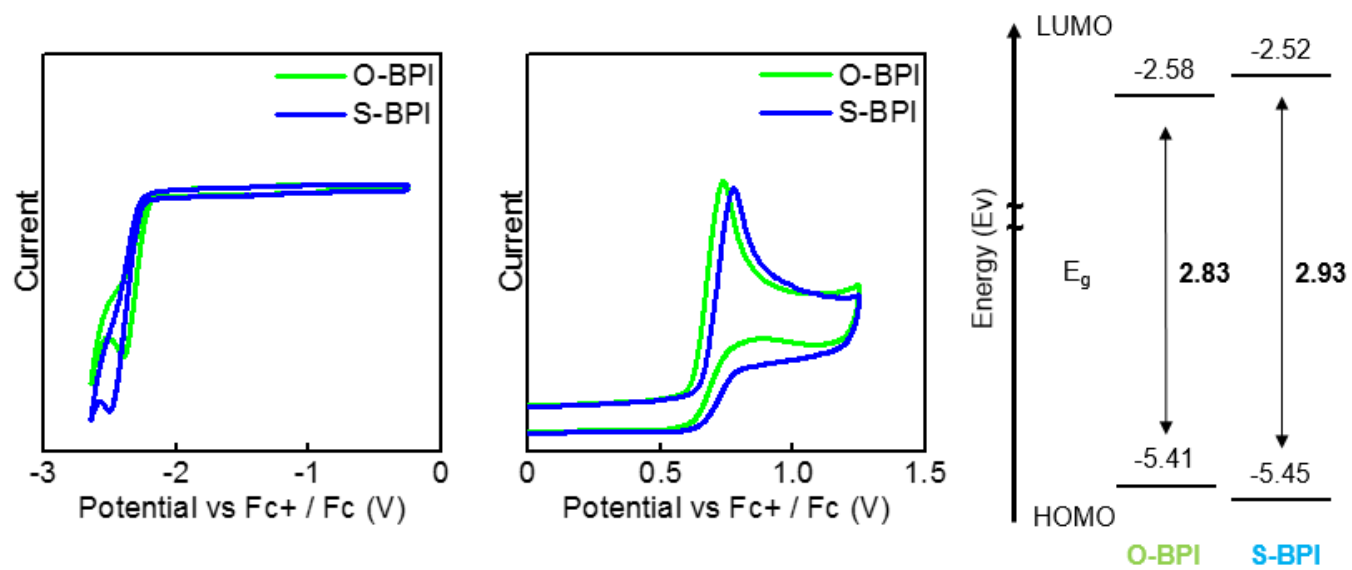

Figure 2. Cyclic voltammograms of $\mathbf{O}-\mathbf{B P I}$ and $\mathbf{S}-\mathbf{B P I}$ from (a) $0 \mathrm{~V}$ to $-2.4 \mathrm{~V}$ and (b) 0 $\mathrm{V}$ to $1.5 \mathrm{~V}$ in $\mathrm{CH}_{2} \mathrm{Cl}_{2}\left(1.0 \times 10^{-3} \mathrm{M}\right)$ with $0.1 \mathrm{M} \mathrm{Bu}_{4} \mathrm{NPF}_{6}$ as a supporting electrolyte, $\mathrm{AgCl} / \mathrm{Ag}$ as a reference electrode, $\mathrm{Pt}$ as working and counter electrodes, and scan rate at $100 \mathrm{mV} / \mathrm{s}$. (c) Energy diagram of O-BPI and S-BPI calculated by CV measurements. 
Table 2. Electrochemical results from CV measurements with O-BPI and S-BPI

\begin{tabular}{lllll}
\hline & $\begin{array}{l}E_{\mathrm{Ox}}{ }^{a} \\
{[\mathrm{~V}]}\end{array}$ & $\begin{array}{l}E_{\mathrm{red}^{b}} \\
{[\mathrm{~V}]}\end{array}$ & $\begin{array}{l}\mathrm{HOMO}^{c} \\
{[\mathrm{eV}]}\end{array}$ & $\begin{array}{l}\mathrm{LUMO}^{d} \\
{[\mathrm{eV}]}\end{array}$ \\
\hline O-BPI & 0.61 & -2.22 & -5.41 & -2.58 \\
S-BPI & 0.65 & -2.28 & -5.45 & -2.52 \\
\hline
\end{tabular}

${ }^{a} E_{\mathrm{Ox}}$ is the onset potential of first oxidation wave.

${ }^{b} E_{\text {red }}$ is the onset potential of first reduction wave.

${ }^{c}$ Calculated from the empirical formula ${ }^{6}, \mathrm{HOMO}=-E_{\mathrm{Ox}}-4.80(\mathrm{eV})$.

${ }^{d}$ Calculated from the empirical formula ${ }^{6}, \mathrm{LUMO}=-E_{\text {red }}-4.80(\mathrm{eV})$. 


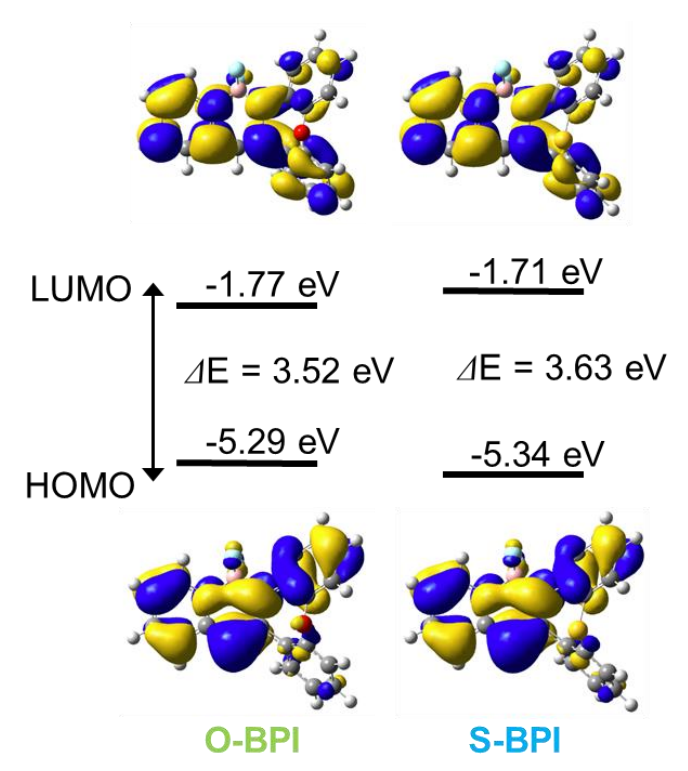

Figure 3. Structures and molecular orbital diagrams of LUMO and HOMO of O-BPI and S-BPI obtained with DFT calculations (B3LYP/6-31G (d)//B3LYP/6-31G (d)). 


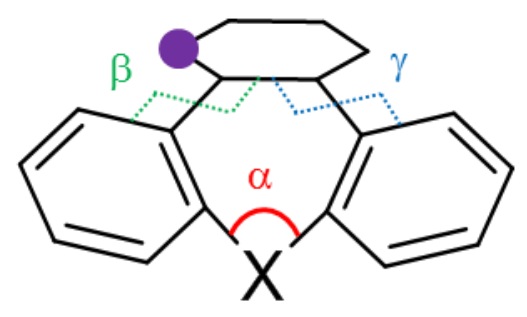

Optimized by B3LYP/6-31G (d)

\begin{tabular}{c|c|c|c}
\hline $\mathrm{X}$ & $\alpha$ (degree) & $\beta$ (degree) & $\gamma$ (degree) \\
\hline $\mathrm{O}$ & 111.84 & 39.09 & 41.56 \\
$\mathrm{~S}$ & 96.27 & 47.53 & 53.35 \\
\hline
\end{tabular}

Figure 4. Molecular structure of O-BPI and S-BPI from quantum chemical calculations. 

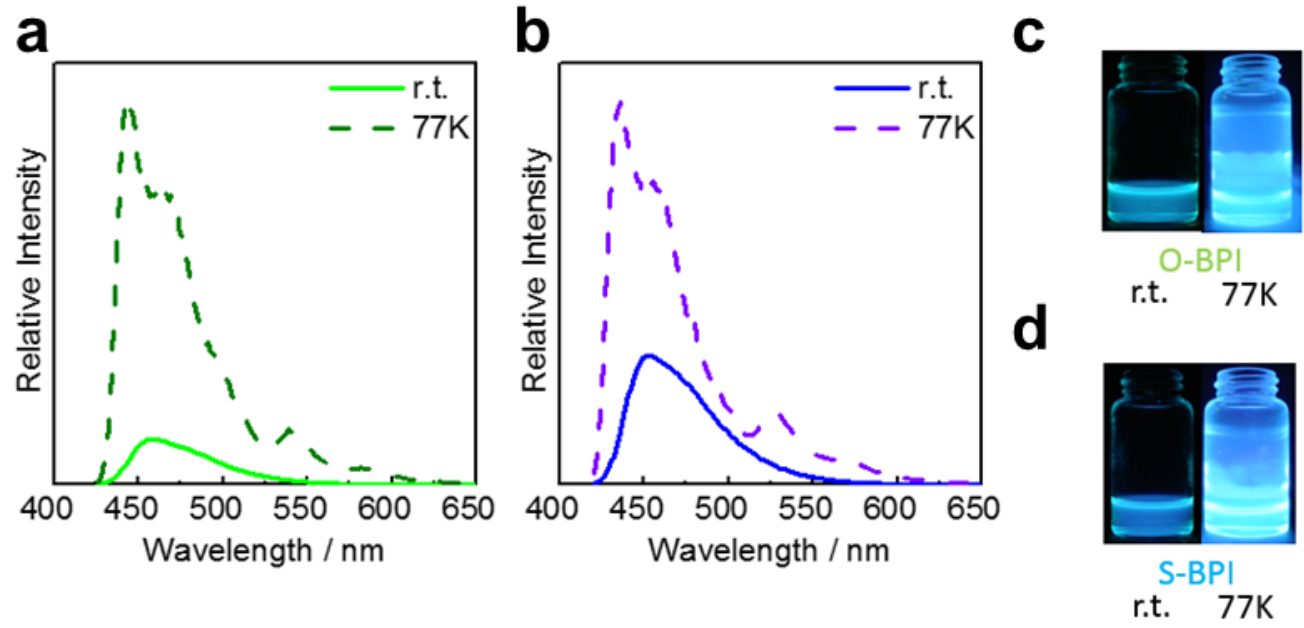

Figure 5. PL spectra of (a) O-BPI and (b) S-BPI in 2-MeTHF $\left(1.0 \times 10^{-5} \mathrm{M}\right)$ at r.t. (solid line) and at $77 \mathrm{~K}$ (dashed line). Photographs of (c) O-BPI and (d) S-BPI in 2-MeTHF $\left(1.0 \times 10^{-5} \mathrm{M}\right)$ at r.t. and $77 \mathrm{~K}$ under UV irradiation $(365 \mathrm{~nm})$. 
Table 3. PL properties of $\mathbf{O}$-BPI and S-BPI in 2-MeTHF $\left(1.0 \times 10^{-5} \mathrm{M}\right)$

\begin{tabular}{lcccc}
\hline & $\begin{array}{c}\lambda_{\mathrm{PL}} \\
(\text { r.t. })\end{array}$ & $\begin{array}{c}\lambda_{\mathrm{PL}} \\
(77 \mathrm{~K})\end{array}$ & $\begin{array}{c}\Phi_{\mathrm{PL}} \\
(\text { r.t. })\end{array}$ & $\begin{array}{c}\Phi_{\mathrm{PL}} \\
(77 \mathrm{~K})\end{array}$ \\
\hline O-BPI & 458 & 444 & 0.07 & 0.75 \\
S-BPI & 452 & 436 & 0.09 & 0.79 \\
\hline
\end{tabular}



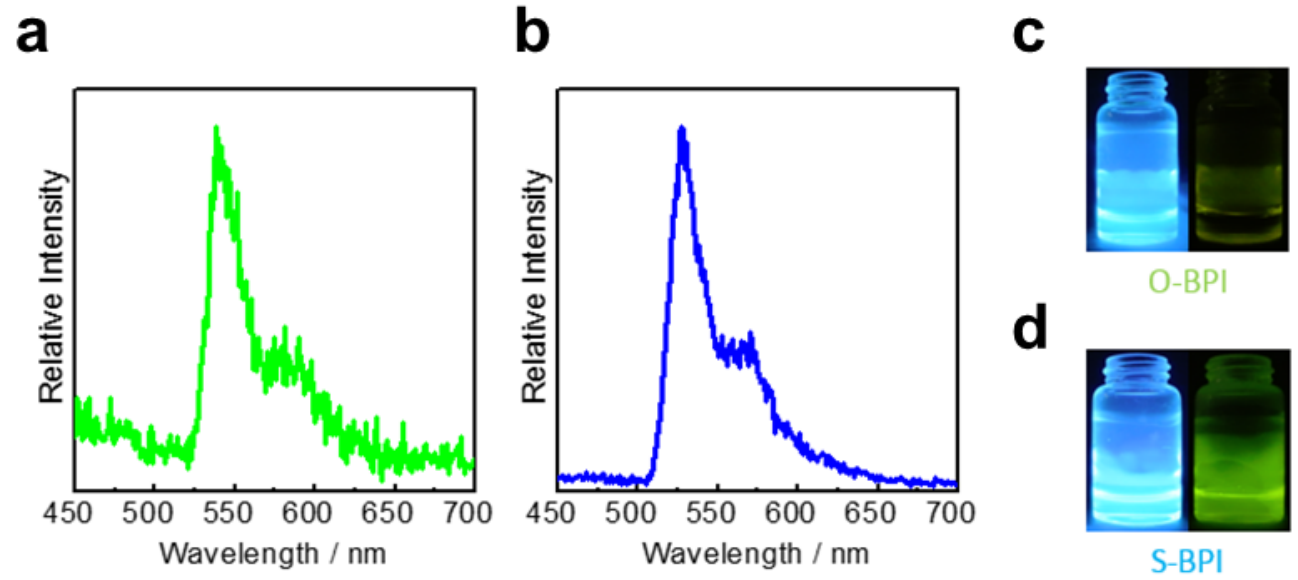

Figure 6. PL spectra of (a) O-BPI and (b) S-BPI in 2-MeTHF $\left(1.0 \times 10^{-5} \mathrm{M}\right)$ at $77 \mathrm{~K}$ which were collected with a $1 \mathrm{~ms}$ delay. Photographs of (c) O-BPI and (d) S-BPI in 2MeTHF $\left(1.0 \times 10^{-5} \mathrm{M}\right)$ at $77 \mathrm{~K}$ under UV irradiation $(365 \mathrm{~nm})$ and immediately after tuning off UV irradiation. 
Table 4. Phosphorescence properties of O-BPI and S-BPI in 2-MeTHF $\left(1.0 \times 10^{-5} \mathrm{M}\right)$ at $77 \mathrm{~K}$

\begin{tabular}{cc} 
& $\lambda_{\mathrm{PL}}[\mathrm{nm}]$ \\
\hline O-BPI & 538 \\
S-BPI & 527 \\
\hline
\end{tabular}


a

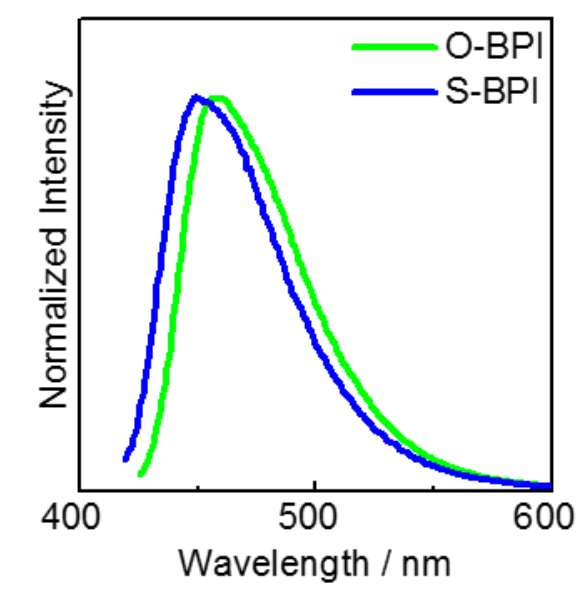

b

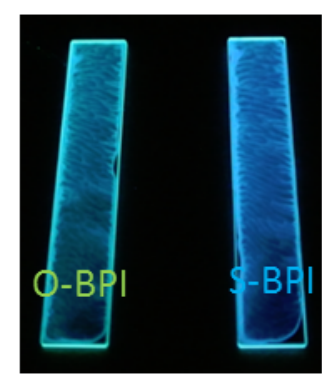

Figure 7. (a) PL spectra of O-BPI and S-BPI in a polymer matrix (1 wt \% in PMMA). (b) Photographs under UV irradiation (365 nm). 
Table 5. PL properties of O-BPI and S-BPI in PMMA

\begin{tabular}{|c|c|c|c|c|}
\hline & $\begin{array}{c}\lambda_{\mathrm{PL}} \\
{[\mathrm{nm}]}\end{array}$ & $\Phi_{\mathrm{PL}}^{c}$ & \multicolumn{2}{|c|}{$\begin{array}{c}\tau^{d} \\
{[\mathrm{~ns}]}\end{array}$} \\
\hline O-BPI & $456^{a}$ & 0.45 & $\begin{array}{c}2.35 \\
(50 \%)\end{array}$ & $\begin{array}{c}4.01 \\
(50 \%)\end{array}$ \\
\hline S-BPI & $450^{b}$ & 0.44 & $\begin{array}{c}1.51 \\
(18 \%)\end{array}$ & $\begin{array}{c}3.59 \\
(82 \%)\end{array}$ \\
\hline
\end{tabular}

${ }^{a}$ Excited at $416 \mathrm{~nm}$

${ }^{b}$ Excited at $409 \mathrm{~nm}$.

${ }^{c}$ Determined as an absolute value.

${ }^{d}$ Excited at $375 \mathrm{~nm}$. 
Table 6. Kinetics of optical processes

\begin{tabular}{|c|c|c|c|c|c|c|}
\hline & \multicolumn{2}{|c|}{ solution } & \multicolumn{2}{|c|}{ crystal } & \multicolumn{2}{|c|}{ PMMA } \\
\hline & $\begin{array}{c}k_{\mathrm{r}} \\
\times 10^{9} \mathrm{~s}^{-1}\end{array}$ & $\begin{array}{c}k \\
k\left(0_{\mathrm{nr}}\right. \\
\left(\mathrm{s}^{-1}\right)\end{array}$ & $\begin{array}{c}k_{\mathrm{r}} \\
\left(\times 10^{9} \mathrm{~s}^{-1}\right)\end{array}$ & $\begin{array}{c}k_{\mathrm{nr}} \\
\left.\times 10^{9} \mathrm{~s}^{-1}\right)\end{array}$ & $\begin{array}{c}k_{\mathrm{r}} \\
\left(\times 10^{9} \mathrm{~s}^{-1}\right.\end{array}$ & $\begin{array}{c}k_{\mathrm{nr}} \\
\left(\times 10^{9} \mathrm{~s}^{-1}\right)^{b}\end{array}$ \\
\hline O-BPI & 0.12 & 1.1 & 0.042 & 0.80 & 0.13 & 0.16 \\
\hline S-BPI & 0.16 & 1.3 & 0.031 & 0.59 & 0.13 & 0.16 \\
\hline
\end{tabular}




\section{GRAPHICAL ABSTRACT}

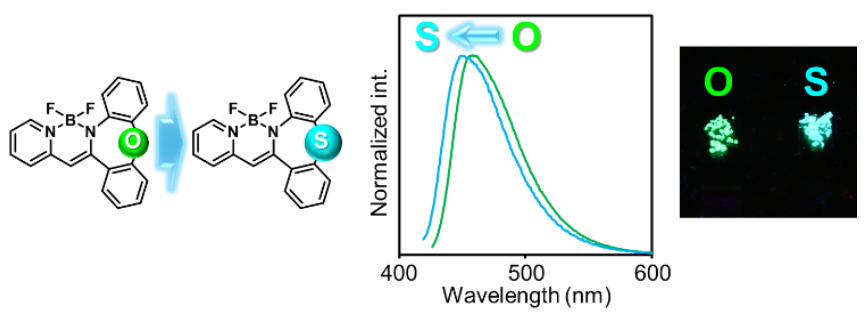

